\title{
EXPERIMENTAL INVESTIGATION OF WAYS TO INCREASE EFFICIENCY OF BREEDING GRAIN MOTH
}

\author{
Valentyna Krutyakova ${ }^{1}$, Olena Molchanova ${ }^{1}$, Volodymyr Bulgakov ${ }^{2}$, Adolfs Rucins ${ }^{3}$ \\ ${ }^{1}$ Engineering and Technology Institute "Biotechnica", Ukraine; \\ ${ }^{2}$ National University of Life and Environmental Sciences of Ukraine, Ukraine; \\ ${ }^{3}$ Latvia University of Life Sciences and Technologies, Latvia \\ arucins@ltk.lv
}

\begin{abstract}
Biological ways to control agricultural pests and weeds (without the use of chemicals) meet current trends in organic farming. Technologies and technical means for the production of entomophages are widely in demand; yet their development so far is in the initial stage. The conducted research allowed improving the technology and equipment for these purposes. In the studies barley was chosen as a food substrate for the moth larvae. The viability of the larval stage was determined by the percentage of the infected grains. These experimental studies were carried out in triplicate, ensuring statistical significance. All the other indicators were determined according to generally accepted methods, with the presence of controls. As a result of the conducted investigation, the optimisation efficiency of the structural parameters of the artificial population of the cereal moth (Sitotroga cerealella Oliv.), which is a substrate for the reproduction of trichograms and other entomophages, was experimentally proved. A relationship has been established between the viability of the biomaterial and the penetration depth of the larvae into the substrate. Application of this selection method during 3 and 6 generations has led to an increase in the biological indicators of the descendants. Based on these studies, it was determined that increase in the density of population of the grain with eggs of the grain moth in the parent culture led to an increase in the viability of caterpillars and pupae of the offspring. The caterpillar viability increased by $5.4 \%$ after 3 generations of selection and by $11 \%$ after 6 generations of selection. Determination of the biological indicators was carried out in the fourth and seventh generations. Viability of the pupae increased by $23.1 \%$ and by $9.9 \%$ after 3 and 6 generations of selection, respectively.
\end{abstract}

Keywords: efficiency, breeding, entomophages, grain moth.

\section{Introduction}

A special place in the technical entomology is occupied by issues related to the successful breeding of entomophages. It is well known that the efficiency of using the biomethod for the pest control in agriculture depends on the quality of the cultivated biomaterial, both entomophages and the substrate for their reproduction (phytophage insects) [1-5]. A traditional object for breeding trichograms and other entomophages is the grain moth (Sitotroga cerealella, Olivier 1789). A set of equipment and technology for industrial production of the grain moth eggs was developed at the Biotechnika Institute [6; 7].

Breeding of grain moths is of an industrial nature, but the biology, ecology and genetics of the species under breeding conditions are not sufficiently studied. There is practically no breeding programme carried out, the culture recreates at the expense of wild population; it is one of the reasons for its high biodiversity. Such material is very sensitive to the impact of environmental and genetic factors affecting the culture under the conditions of technocenosis due to insufficient adaptation. To increase the viability and productivity of grain moths, both the methods for creating optimal conditions of breeding and individual breeding and individual selective-and-genetic methods can be used [8-13].

Insect breeding is generally associated with violation of the spatial structure of the population in the technocenosis, inherent to this species in nature. An increase in the planting density of individuals negatively affects the nature of endocrine processes in insects, their behavioural reactions, and the overall viability of cultures $[14 ; 15]$.

Therefore the development of methods for the optimisation of the spatial structure of the insect cultures is an important and promising task of technical entomology. It is believed that prolonged cultivation often leads to degeneration and death of the culture. On the one hand, this is explained by the fact that the insect cultivation takes place in the optimum zone, and the impact of the natural selection factors is weakening. On the other hand, an artificial population contains a limited set of genotypes, and, as it is known, a decrease in the heterogeneity of a population leads to a decrease in the viability of individuals. That is why the modern technical entomology has a whole arsenal of 
methods for the optimisation of artificial insect populations, developed in accordance with the purposes of breeding programs and the peculiarities of biology and ecology of the cultivated species [16-18]. At the same time, the studies of recent years have shown the existence of homeostatic properties of artificial populations, which should be taken into account when optimising the biomaterial [19-21].

At present it has been established that the efficiency of trichograms and other carnivorous insects depends on the viability and quality of eggs of the grain moth (lacewing ordinary, carnivorous clips macrolofus and orius, coccinellid, etc.). Optimisation of the culture according to indicator "female fertility" will favour an increase in the economic efficiency of production [11;22]. It is known that the grain moth has negative phototaxis, the caterpillars tend deep into the substrate, although this is associated with a number of difficulties [19;23].

The purpose of the research is to develop new methods for optimising the laboratory culture of cereal moth (Sitotroga cerealella Oliv.), aimed at increasing the viability of the biomaterial, taking into account the peculiarities of the biology and ecology of this type of phytophage.

\section{Materials and methods}

Breeding of insects was carried out under conditions, optimal for the grain moth - at the air temperature $23-25^{\circ} \mathrm{C}$, relative air humidity $15-16 \%$. In the process of laying eggs the butterflies were kept at $21-25^{\circ} \mathrm{C}$. By biological peculiarities, as a rule, one phytophage caterpillar insinuates into one barley grain $[1 ; 18]$. During the studies of the grain moth the following indicators were taken into account: the caterpillar viability (\%); the average mass of female pupae $(\mathrm{mg})$, the average female fertility (pcs.), the female lifespan (days), the caterpillar hatching from the eggs (\%) [1].

The spatial structure of the experimental culture was optimised by separation and selection in a number of generations of individuals that are located at a certain depth in the barley grain, as well as by selection of individuals under the conditions of cultivation with an increased density in the substrate $[21 ; 23]$. In the control variant all the infections were carried out at a ratio of the egg weight (g) to the grain weight $(\mathrm{kg})$ of $1: 1$.

Two series of experiments were carried out with selection according to the following criteria: competition of caterpillars in the process of population of the grain and their depth of distribution in the substrate.

Experiment 1. Cultivation of the cereal moth on barley for six generations with the infection of the grain at the rate of $2 \mathrm{~g}$ of eggs per $1 \mathrm{~kg}$ of barley, the biological indicators being determined after the third and sixth generations.

Experiment 2. Selection for six generations of the grain moths according to the depth of penetration into the food substrate (up to $1 \mathrm{~cm}$ - the upper layer, $3-4 \mathrm{~cm}-$ the lower layer). For breeding, only insects from the lower layer were used.

Each variant of the experiment corresponded to a control under which no effect on insects was carried out, and they were cultivated under conditions, optimal for the species. Technological operations with grain were carried out in cassettes (Fig. 1). The barley grain of $7 \mathrm{~kg}$ was placed in the cassettes. For thermal disinfection and moistening of grain in the cassettes, a grain conditioner was used (Fig. 2). The air conditioner allows adjustment of the grain processing time and synchronisation of the start of the cycle with a pre-set water temperature and provides for blocking the movement of the cassette with grain for immersion until the specified water temperature is reached. This processing method makes it possible to obtain moistened, disinfected, soft grain, which contributes to better introduction of the grain moth into it.

The barley cassettes, processed in the grain conditioner, were placed on the grain rack (Fig. 3). The rack is mobile, provided with a possibility of full extension of the grain cartridge to ensure ease of use in the process of development of the grain moths. The design of the rack provides a tray for collecting the garbage and excess liquid.

The experiment was carried out directly in grain cartridges. The eggs of the grain moth were evenly distributed on the grain. After hatching from the eggs the caterpillars were introduced into grains that were at different depths of the barley layer. 


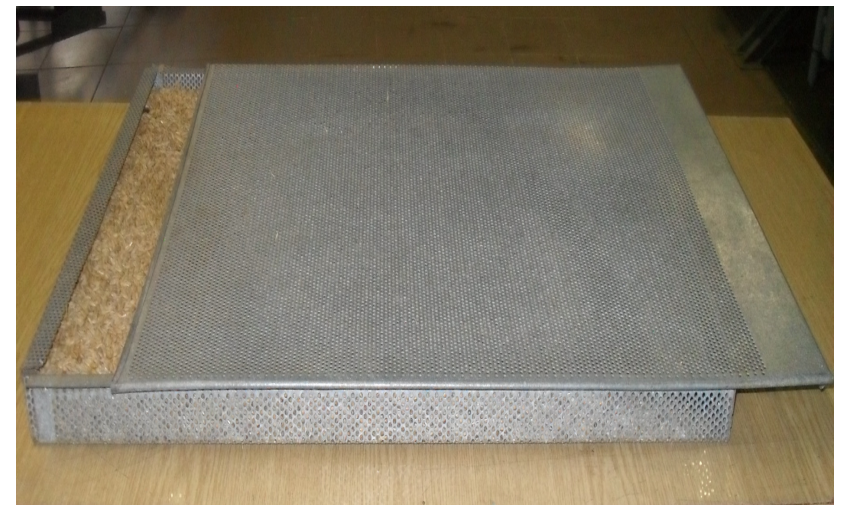

Fig. 1. Cassette with a cover

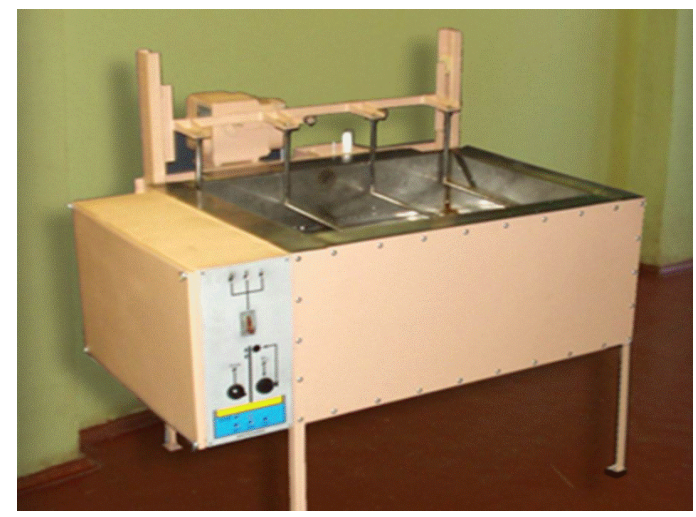

Fig. 2. Grain conditioner

The viability of the caterpillars was determined by the percentage of the infected barley grains, selecting four replicates of 100 grains each on the 20th day after infection and analysing them (by cutting the grains). To determine the mass of pupae, the grains were cut after the first butterflies began to fly out of the grain (Fig. 4). All the other indicators were determined by generally accepted methods.

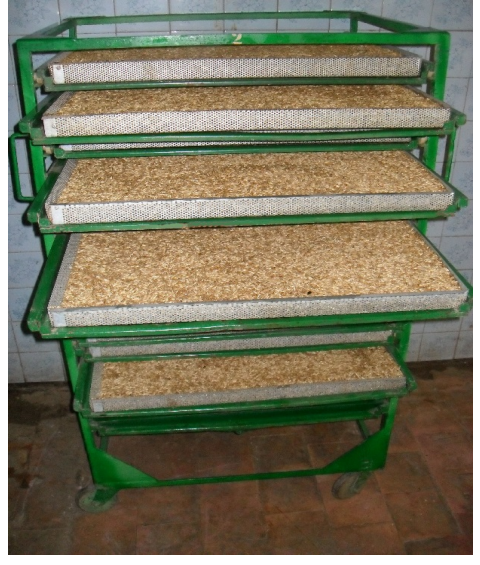

Fig. 3. Rack for grain

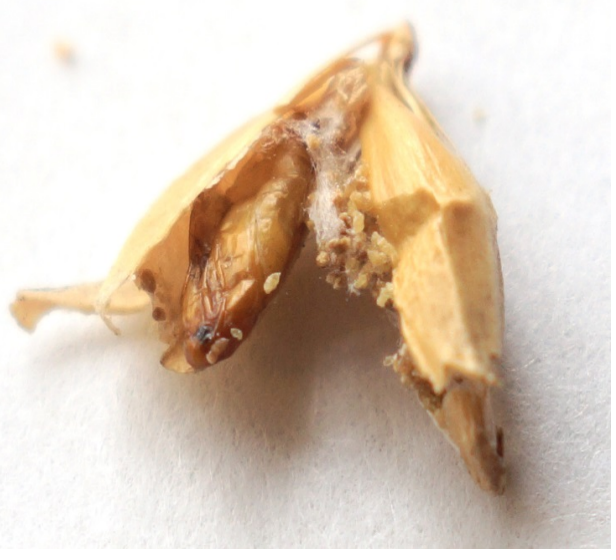

Fig. 4. Cut barley grain with a grain moth pupa

At the beginning of the departure of the imago from the grain, the cassettes were closed with lids and installed vertically in the box (Fig. 5).

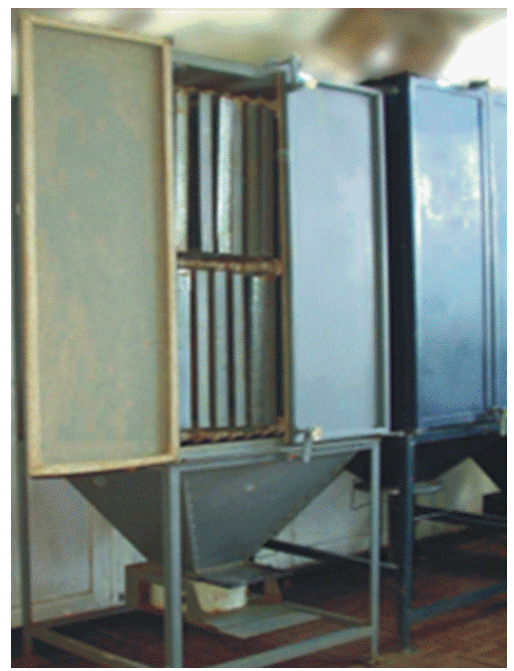

Fig. 5. Box intended for the birth 
The box is intended for the birth and collection of the imago grain moths. The butterflies by their biological peculiarities move to the receiving cage, which is located below at the base of the device. The number of the obtained butterflies and eggs in all variants of the experiments were determined daily.

All the test variants were set in triplicate; the number of individuals in the replicates was statistically significant. The resulting digital material was processed on a PC in the programme Excel by the method of variation statistics, using Student's t-test.

\section{Results and discussion}

Experiment 1. From the moment of hatching of the caterpillars from the eggs to the departure of the imago the development took place in the food substrate (the barley grain). The egg-laying period continued - 4-12 days. The bulk of the butterfly eggs were laid in the first five days [17].

The results of the influence of the density of the parental generation on the biological indicators of the offspring of the grain moths were obtained (Fig. 6).

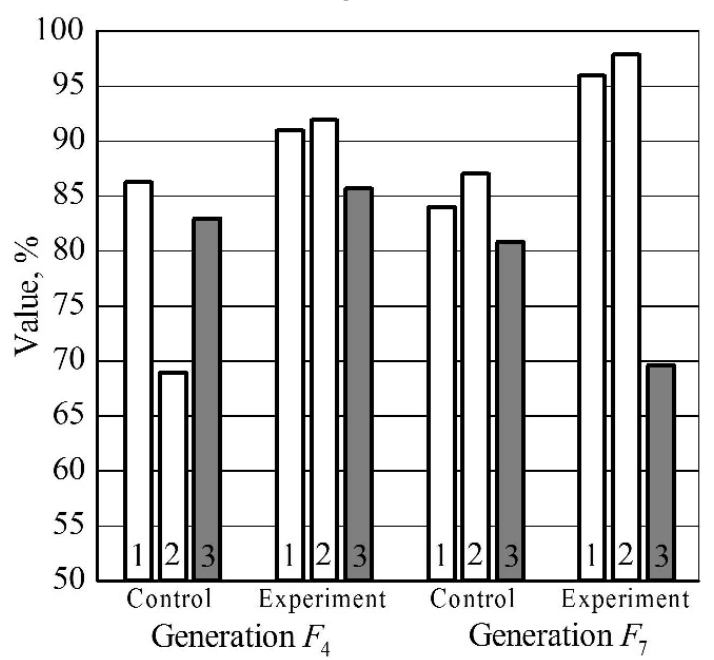

Fig. 6. Biological indicators of the offspring of the grain moth culture with different density content of the parental culture: 1 - caterpillar viability; 2 - viability of pupae;

3 - hatching of caterpillars from the eggs

An increase in the density of population of the grain with eggs of the grain moth in the parent culture led to an increase in the viability of caterpillars and pupae of the offspring. The caterpillar viability increased by $5.4 \%$ after 3 generations of selection and by $11 \%$ after 6 generations of selection. Determination of the biological indicators was carried out in the fourth and seventh generations (F4, F7). Viability of the pupae increased by $23.1 \%$ and by $9.9 \%$ after 3 and 6 generations of selection, respectively. During the experiment an increase in the rate of hatching of caterpillars from the eggs in the offspring was noted both after 3 and 6 generations of selection.

A tendency toward an increase in the mass of females, their average fecundity and life expectancy in the 7 th generation was noted (Table 1).

Table 1

Biological indicators of the descendants of the grain moth at different densities of the content of the parent culture

\begin{tabular}{|c|c|c|c|c|}
\hline \multicolumn{2}{|c|}{ Variants } & \multicolumn{2}{c|}{ Average } & \multirow{2}{*}{$\begin{array}{c}\text { Lifespan of females, } \\
\text { days }\end{array}$} \\
\cline { 1 - 3 } $\begin{array}{c}\text { Density of the } \\
\text { content }\end{array}$ & $\begin{array}{c}\text { Generation of } \\
\text { selection }\end{array}$ & $\begin{array}{c}\text { Female mass, } \\
\mathrm{mg}\end{array}$ & $\begin{array}{c}\text { Female fertility, } \\
\text { pcs. }\end{array}$ & $16.2 \pm 1.5$ \\
\hline $1: 1$ & IV & $8.3 \pm 0.2$ & $19.2 \pm 4.2$ & $17.1 \pm 1.3$ \\
\hline $2: 1$ & IV & $9.2 \pm 3.7$ & $18.9 \pm 3.3$ & $16.8 \pm 1.4$ \\
\hline $1: 1$ & VII & $9.1 \pm 1.9$ & $19.1 \pm 4.3$ & $17.6 \pm 1.3$ \\
\hline $2: 1$ & VII & $9.5 \pm 1.8$ & $20.8 \pm 4.2$ & \\
\hline
\end{tabular}


Experience 2. The impact was determined of the selection of the grain moths in a number of generations for the infection of barley grain from the upper and lower layers of the substrate upon the biological indicators of the offspring (Table 2).

Table 2

\section{Biological indicators of the descendants of the grain moths from various spatial layers of the substrate}

\begin{tabular}{|l|c|c|}
\hline \multicolumn{1}{|c|}{ Layer of substrate } & $\begin{array}{c}\text { Viability of } \\
\text { caterpillars, \% }\end{array}$ & $\begin{array}{c}\text { Part of caterpillars that } \\
\text { spawned, \% }\end{array}$ \\
\hline Upper (after 3 generations' selection) & $83.4 \pm 1.2$ & $80.1 \pm 4.1$ \\
\hline Lower (after 3 generations' selection) & $88.4 \pm 1.1$ & $85.7 \pm 3.8$ \\
\hline Upper (after 6 generations' selection) & $83.8 \pm 1.4$ & $81.0 \pm 3.9$ \\
\hline Lower (after 6 generations' selection) & $94.9 \pm 1.6$ & $89.9 \pm 2.0$ \\
\hline Culture without selection (control) & $87.3 \pm 1.1$ & $82.1 \pm 1.8$ \\
\hline
\end{tabular}

From the above data it is evident that the viability of individuals of the cereal moth from the lower layers of the substrate, after six generations of selection, was by $7.6 \%$ higher than the viability in the control variant and by $11.1 \%$ in the variant from the upper layer of the substrate. A tendency was established towards an increase in the mass of females, their average fecundity, and longevity (Fig. 7).

When breeding the cereal moth on the barley grain according to the accepted technology, $1 \mathrm{~g}$ of the grain moth eggs is used for the infection of $1 \mathrm{~kg}$ of grain. A 2-fold increase in the ratio of the mass of eggs of a grain moth to the amount of grain (up to $2 \mathrm{~g}$ per $1 \mathrm{~kg}$ ) practically does not lead to an increase in the grain contamination, which increases only by $14 \%$. This is because the caterpillars of the second and subsequent days of exit move to the already prepared holes in the grain, made by the caterpillars that came out earlier, where the predecessors die or drive out the predecessors. The resulting increase in culture indicators is due to the fact that, as a result of competition for the substrate for six generations, the selection of the most competitive and, therefore, more viable cereal moth genotype takes place.

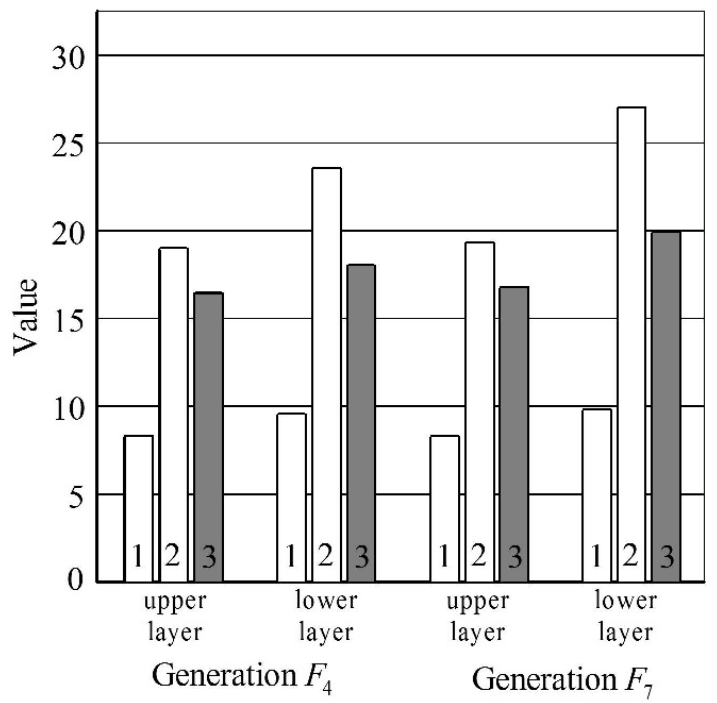

Fig. 7. Biological indicators of the population of the cereal moth after selection in several generations by the spatial distribution of caterpillars in the substrate: 1 - average female mass, $\mathrm{mg} ; 2$ - average fertility of the female, pcs; 3 -female lifespan, days

With the existing technology of production of the grain moth eggs in barley there takes place irrational use of the food substrate by the caterpillars. In addition, the main part of the caterpillars is concentrated in the upper layers of the grain, and only a small part penetrates into the deeper layers of the substrate. We consider this property possible to use in order to optimise the spatial structure of the population based on differences in the motor activity of the larvae. If in caterpillars of the grain moth by their motor activity is understood the ability to penetrate deep into the substrate, then such caterpillars should be more viable. When conducting the research for six generations, a biomaterial, 
taken from two layers of grain, the upper and lower, was used to infect the grain. In the fourth and seventh generations the biological indicators were recorded. The existence of a direct relationship between the intensity of the motor activity of the caterpillars of the grain moth and their viability has been established. The method of selection of the grain, infected with a moth from the lower layers of the substrate, can be used to increase the viability of the entomoculture during the mass cultivation of the phytophage to obtain eggs.

\section{Conclusions}

1. Two methods have been proposed and experimentally confirmed to increase the viability of the grain moths during their mass dilution. Increasing the density of the caterpillar content for six generations contributes to the formation of a highly viable phytophage genotype.

2. The existence of a direct correlation between the depth of penetration of the grain moth caterpillars into the substrate and their viability makes it possible to recommend this technique for optimising the spatial structure of the insect culture in order to increase the efficiency of breeding grain moths.

3. The obtained experimental data can be used to improve the process of industrial production of the grain moth eggs, and they will also be useful in the formation of uterine phytophage cultures.

\section{References}

[1] Zlotin A. Z. Theoretical foundation of the mass breeding of insects Entomological review. 1981; 60(3). pp. 494-510.

[2] Greenberg Sh. M., Podberezska L. V. Comparative evaluation of trichogram's quality factors, which breeded on eggs of different organisms. Plant protection. 1983; 30. pp. 39-41.

[3] Da Silva Krechemer, F., Foerster, L. A. Mass production of Trichogramma spp. using Mythimna sequax eggs stored in liquid nitrogen. BioControl. 2016; 61(5): pp. 497-505.

[4] St-Onge, M., Cormier, D., Todorova, S., Lucas, É. Conservation of Ephestia kuehniellaeggs as hosts for Trichogramma ostriniae. Journal of Applied Entomology. 2015; 140(3). pp. 218-222.

[5] Крутякова В., Чернова И., Молчанова Е., Должикова И. Основные подходы для обеспечения качества энтомологической продукции (The main approaches to ensure the quality of entomological products. Техника и технологии АПК, 2015, №11(74). pp. 30-31. (In Russian)

[6] Крутякова В. И., Молчанова Е. Д., Бельченко В. М., Шейкин Б. М., Ходорчук В. Я., Баркар В. П., Лимарь И. В. Технологии разведения хищных насекомых и клещей в искусственных условиях (Technologies for breeding predatory insects and ticks in artificial conditions.). Материалы Международной научной конференции «Защита растений в традиционном экологическом земледелии», Кишинев, 2018. pp. 236-241. (In Russian)

[7] Старчевський И.П., Бельченко В.М., Гончарук А.И., Шейкин Б.М. Технологическое оборудование для переоснащения, реконструкции и ремонта производства трихограммы сети биофабрик и биолабораторий (Technological equipment for re-equipment, reconstruction and repair of trichogram production of a network of biofactories and biological laboratories). Сборник научных трудов «Технико-технологические аспекты развития и производства техники и технологий для сельского хозяйства Украины», 2015, Выпуск. 8 (22), книга 2. pp. 182-186. (In Russian)

[8] Cohen A.C. Ecology of Insect Rearing Systems: A Mini-Review of Insect Rearing Papers from 1906-2017. Advances in Entomology. 2018; 6(2). pp. 86-115.

[9] Pitcher, S. A., Hoffmann, M. P., Gardner, J., Wright, M. G., \& Kuhar, T. P. Cold storage of Trichogramma ostriniae reared on Sitotroga cerealella eggs BioControl. 2002; 47(5). pp. 525-535.

[10]Bai, B., Luck, R. F., Forster, L., Stephens, B., \& Janssen, J. A. M. The effect of host size on quality attributes of the egg parasitoid, Trichogramma pretiosum. Entomologia Experimentalis et Applicata. 1992; 64(1). pp.37-48.

[11] Abdel-Salam, A. H., \& Abdel-Baky, N. F. Life table and biological studies of Harmonia axyridis Pallas (Col., Coccinellidae) reared on the grain moth eggs of Sitotroga cerealella Olivier (Lep., Gelechiidae). Journal of Applied Entomology. 2001; 125(8): pp. 455-462. 
[12] Adashkevich B. P. Breeding Angoumois grain moth in biofarms. Agriculture of Uzbekistan. 1987, No 4. pp. 39-40.

[13] Abashkin A.S., Grinberg SH.M., Gorban M.P. State of affairs and perspective breeding trichogram in biofarms. Trichogram in plant protection. Collection of scientific papers. - M., Agropromizdat. 1988: pp. 3-12.

[14]Zlotin A. Z. Golovko V. A. Ecology of populations and cultures of insect. 1998, Kharkov; 231 p.

[15] Benkovskaya G.V., Nikonorov Yu. M. Assortative mating and maintenance of intrapopulation polymorphism in wild populations and laboratory cultures of insects Biology Bulletin Review. 2015, 76(6). pp. 421-428.

[16] Paliy M. V., Porban G. V., Grinberg SH. M. Peculiarities of mass breeding of Angoumois grain moth. Mass breeding of insects. Kishinev, 1988. pp. 16-17.

[17] Vorontsova N. L. Biological peculiarities of breeding of Angoumois grain moth on laboratory population. Mass breeding of insects. Kishinev, 1984. pp. 52-55.

[18] Adashkevich B. P. Entomophage standardization. Plant protection. 1988. pp. 10:16.

[19] Markina T.Yu. The theoretical basis of homeostasis maintenance in artificial insect populations and control of their condition. Biolohiia ta valeolohiia. 2017, 19. pp.58-68.

[20] Markina T.Y. New approaches to quality control for cultures of insects for rearing. Biosystems Diversity. 2016, 24(1): pp.164-172. (In Russian).

[21] Markina T.Yu., Benkovskaya G.V. Mechanisms of homeostasis maintenance in laboratory populations of insects. Russian Journal of Ecology. 2015, 46(4). pp. 365-369.

[22] Greco, C. F., \& Stilinovic, D. Parasitization performance of Trichogrammaspp. (Hym., Trichogrammatidae) reared on eggs of Sitotroga cerealella Oliver (Lep., Gelechiidae), stored at freezing and subfreezing conditions. Journal of Applied Entomology, 1998, 122(1-5). pp. 311314.

[23] Markina T. Yu. Changes in structure parameters of silkwarm populations Bombyx mori L. (Lepidoptera, Bombycidae) under the optimization of cultivation. The Bulletin of Kharkiv National Agrarian University. Series "Biology". 2009; 1 (16). pp. 99-105. 